\title{
Differential effect of flavonoids on glycosaminoglycan content and distribution in skin fibroblasts of patients with type I osteogenesis imperfecta
}

\author{
ANNA GALICKA $^{1}$, JOLANTA NAZARUK ${ }^{2}$ and MARTA BRUCZKO ${ }^{3}$ \\ Departments of ${ }^{1}$ Medical Chemistry, ${ }^{2}$ Pharmacognosy, and ${ }^{3}$ Pediatric Orthopaedics and Traumatology, \\ Medical University of Bialystok, 15-230 Bialystok 8, Poland \\ Received January 14, 2010; Accepted March 24, 2010
}

DOI: $10.3892 / \mathrm{mmr} 00000294$

\begin{abstract}
We recently reported that, in osteogenesis imperfecta (OI) type I with diminished type I collagen biosynthesis, flavonoids such as apigenin 7-O-glucuronide, apigenin 7-O-methylglucuronide and pectolinarin normalized the level of collagen type I without affecting total protein synthesis. In addition to collagen, glycosaminoglycans (GAGs) play an important role in the formation of a functional supramolecular complex in the extracellular matrix, and any changes in their content and/or composition may be involved in the OI phenotype. We previously detected a marked increase in sulphated GAG content in the OI fibroblasts of more severely affected patients (OI types II and III). These alterations were more pronounced in medium than in cells. Although, in OI type I cells, the increase observed in medium was much smaller (approximately 1.5-fold), it resulted in an increase of approximately 3 -fold of the GAG to collagen type I ratio. Therefore, in the potential pharmacotherapy of OI type I with flavonoids, their effect on GAG level may be of importance. In the OI cells, some of the tested flavonoids applied at a concentration of $30 \mu \mathrm{M}$ affected GAG content in quite the opposite way than type I collagen. Aglicones inhibiting collagen synthesis caused a marked increase in GAG concentration in medium, in contrast to the flavonoid glycosides, which exerted a stimulatory effect on type I collagen synthesis, but had a different effect on GAG content and distribution. Among these, apigenin 7-O-methylglucuronide did not affect GAG level or secretion, and thus may potentially be used in $\mathrm{OI}$ type I pharmacotherapy in patients with normal GAG content. However, in patients with increased concentrations of GAG, pectolinarin, which decreases GAG content by approximately $40 \%$, may be more beneficial.
\end{abstract}

Correspondence to: Dr Anna Galicka, Department of Medical Chemistry, Medical University of Bialystok, 15-230 Bialystok 8, Poland

E-mail: angajko@umwb.edu.pl

Key words: osteogenesis imperfecta, flavonoids, glycosaminoglycan in fibroblasts

\section{Introduction}

Osteogenesis imperfecta $(\mathrm{OI})$ is a genetically inherited disorder of the connective tissues characterized by bone fragility and skeletal deformities (1-5). OI presents with a broad range of clinical severity, ranging from multiple fracturing and perinatal death to a mild form that may elude clinical detection. OI has been categorized into four major clinical types based on clinical features as well as on radiological and genetic criteria (3). Biochemical and molecular genetic studies have shown that the vast majority of affected individuals have mutations in either the COL1A1 or COL1A2 genes, which encode the chains of type I procollagen, the major structural protein of bone $(1,2,4)$. Recently, four new groups of patients have been defined in terms of clinical severity with the exclusion of type I collagen gene mutations (5). The lack of a relationship between collagen mutation and phenotype suggests the involvement of other modifying factors. Studies of this disorder in various tissues reflect an altered structure and/or metabolism of one or more of the extracellular matrix components, including collagen, glycosaminoglycans (GAGs) and/or proteoglycans (PGs) (6-8). GAGs are known to be involved in interactions with collagen type I and in the process of fibrillogenesis (9), thus any alterations in GAG synthesis, modification or secretion could affect these processes.

Previously, we demonstrated that disturbances of collagen type I biosynthesis in the skin fibroblasts of patients with OI type I were normalized by treatment of the cells with certain flavonoid glycosides (10). Flavonoids, which are plant polyphenolic compounds, are known to have a number of biological activities, including anti-oxidant, anti-radical, anti-flammatory, anti-microbial, anti-allergy and anti-apoptic effects (11-13). This study was undertaken to investigate the influence of bioactive compounds isolated from the thistles Cirsium rivulare (Jacq.) Mill., Cirsium palustre (L.) Scop. and blue fleabane Erigeron acris L. (14-16) on GAG in OI fibroblasts.

\section{Materials and methods}

Fibroblast cultures. Skin fibroblast cultures from OI patients and healthy age-matched control subjects were grown to 
Table I. Structure of the investigated flavonoids.

\begin{tabular}{|c|c|c|c|c|c|c|c|}
\hline \multirow[t]{2}{*}{ Compound } & \multirow[t]{2}{*}{ No. } & \multicolumn{6}{|c|}{ Substitution pattern } \\
\hline & & $\mathrm{R}_{1}$ & $\mathrm{R}_{2}$ & $\mathrm{R}_{3}$ & $\mathrm{R}_{4}$ & $\mathrm{R}_{5}$ & $\mathrm{R}_{6}$ \\
\hline Apigenin & 1 & $\mathrm{H}$ & $\mathrm{H}$ & $\mathrm{OH}$ & $\mathrm{H}$ & $\mathrm{OH}$ & $\mathrm{H}$ \\
\hline Tricin & 2 & $\mathrm{H}$ & $\mathrm{H}$ & $\mathrm{OH}$ & $\mathrm{OCH}_{3}$ & $\mathrm{OH}$ & $\mathrm{OCH}_{3}$ \\
\hline Isokaempferide & 3 & $\mathrm{OCH}_{3}$ & $\mathrm{H}$ & $\mathrm{OH}$ & $\mathrm{H}$ & $\mathrm{OH}$ & $\mathrm{H}$ \\
\hline Quercetin & 4 & $\mathrm{OH}$ & $\mathrm{H}$ & $\mathrm{OH}$ & $\mathrm{OH}$ & $\mathrm{OH}$ & $\mathrm{H}$ \\
\hline Apigenin 7- $O$-glucuronide & 5 & $\mathrm{H}$ & $\mathrm{H}$ & O-glucuronyl & $\mathrm{H}$ & $\mathrm{OH}$ & $\mathrm{H}$ \\
\hline Apigenin 7-O-methylglucuronide & 6 & $\mathrm{H}$ & $\mathrm{H}$ & $O$-methylglucuronyl & $\mathrm{H}$ & $\mathrm{OH}$ & $\mathrm{H}$ \\
\hline Apigenin 7-O-glucoside & 7 & $\mathrm{H}$ & $\mathrm{H}$ & $O$-glucosyl & $\mathrm{H}$ & $\mathrm{OH}$ & $\mathrm{H}$ \\
\hline Skutellarein 7- $O$-glucuronide & 8 & $\mathrm{H}$ & $\mathrm{OH}$ & $O$-glucuronyl & $\mathrm{H}$ & $\mathrm{OH}$ & $\mathrm{H}$ \\
\hline Pectolinarin & 9 & $\mathrm{H}$ & $\mathrm{OCH}_{3}$ & O-rutinosyl & $\mathrm{H}$ & $\mathrm{OCH}_{3}$ & $\mathrm{H}$ \\
\hline Isokaempferide 7-O-glucoside & 10 & $\mathrm{OCH}_{3}$ & $\mathrm{H}$ & $O$-glucosyl & $\mathrm{H}$ & $\mathrm{OH}$ & $\mathrm{H}$ \\
\hline Quercetin 3-O-glucoside & 11 & $O$-glucosyl & $\mathrm{H}$ & $\mathrm{OH}$ & $\mathrm{OH}$ & $\mathrm{OH}$ & $\mathrm{H}$ \\
\hline
\end{tabular}

confluence in Dulbecco's modified Eagle's medium (DMEM) with $10 \% \mathrm{FBS}, 50 \mathrm{U} / \mathrm{ml}$ penicillin, $50 \mu \mathrm{g} / \mathrm{ml}$ streptomycin and $2 \mathrm{mmol} / \mathrm{l} \mathrm{L}$-glutamine at $37^{\circ} \mathrm{C}$ in a $5 \% \mathrm{CO}_{2}$ incubator. The biopsies were obtained with the approval of the Ethics Committee of the Medical University of Bialystok and with written parental consent. Cells were counted in a hemocytometer and cultured at a density of $1 \times 10^{6}$ cells/well in $2 \mathrm{ml}$ growth medium in 6-well plates (Costar). For the experiments, confluent cells were used to eliminate growth-related events.

Effect of flavonoids on GAG content in skin fibroblasts. The confluent cells were pre-incubated in fresh serum-free medium for $2 \mathrm{~h}$. The flavonoids were dissolved in dimethyl sulfoxide (DMSO) and added to the medium at a final concentration of $30 \mu \mathrm{M}$, then incubated with the cells for $24 \mathrm{~h}$. The concentration of $30 \mu \mathrm{M}$ was selected on the basis of previous experiments, in which higher concentrations of the tested flavonoids proved in most cases to be toxic to cells. The same concentration of DMSO solution was applied to cells as a control. After incubation, the exposure medium was removed and stored for analysis of the secreted GAGs. The monolayers were washed four times with sterile $10 \mathrm{mM}$ PBS (pH 7.4), and the cell membranes were disrupted using a sonicator. Aliquots of the homogenate were removed for DNA measurement, and the remaining homogenate was used for the analysis of GAG content according to the method of Barbosa et al (17).

Briefly, cellular and supernatant proteins were digested in a solution of $50 \mu \mathrm{g} / \mathrm{ml}$ proteinase $\mathrm{K}$ in $100 \mathrm{mM} \mathrm{K}_{2} \mathrm{HPO}_{4}$ (pH 8.0) at $56^{\circ} \mathrm{C}$ overnight. Proteinase $\mathrm{K}$ was then inactivated by heating for $10 \mathrm{~min}$ at $90^{\circ} \mathrm{C}$. In order to eliminate DNA, which interferes with this assay, digested samples were filtered through an Ultrafree-MC filter (Millipore Corp., USA). 1,9-dimethylmethylene blue (DMMB) (1 ml) was added to $100 \mu \mathrm{l}$ of the sample and vigorously vortexed for $30 \mathrm{~min}$ to promote the complexation of the GAGs with the DMMB. The GAG/DMMB complex was then separated from the solution by centrifugation $(12,000 \mathrm{x} \mathrm{g}, 10 \mathrm{~min})$. The pellet was dissolved by the addition of $1 \mathrm{ml}$ of decomplexation solution (4 M GuHCl, pH 6.8) containing $10 \%$ propan-1-ol, and agitated for $30 \mathrm{~min}$. Absorbance was measured at $656 \mathrm{~nm}$.<smiles>[R]c1cc(-c2oc3cc([R3])c([R4])c(O)c3c(=O)c2[R])cc([R4])c1[R5]</smiles>

Figure 1. Molecular structure of the flavonoids.

Sulphated GAG quantities were determined by comparison with a calibration curve of CS solutions and expressed as $\mu \mathrm{g}$ of GAGs per $\mu \mathrm{g}$ of DNA. DNA was assayed in the fibroblasts by fluorometric measurement using Hoechst 33258 staining (18).

Statistical analysis. Data are presented as the mean \pm SD of three assays. The results were subjected to statistical analysis using one-way analysis of variance (ANOVA) followed by the Kruskal-Wallis rank sum test, with $\mathrm{P}<0.05$ considered significant.

\section{Results}

Since the synthesis of sulphated GAGs is dependent on the age of the fibroblast donor, to avoid discrepancies due to age, the concentrations of the GAGs were compared between the patients and the age-matched controls. In the fibroblasts of patients with severe type III and lethal type II OI, the sulphated GAG content was markedly higher than in the controls. This difference was more pronounced in the medium than in the cells (Table II). In a newborn with OI type II and a Gly388 $\rightarrow$ Arg mutation in the COL1A1 gene (19), the level of sulphated GAGs was 5-fold higher in cells and 8.1-fold higher in medium with respect to the age-matched control. In siblings with OI type III (No. 2a and 2b) and differential expression of the phenotype whose fibroblasts secreted collagen type I with faster electrophoretic mobility, suggesting deletion as a 

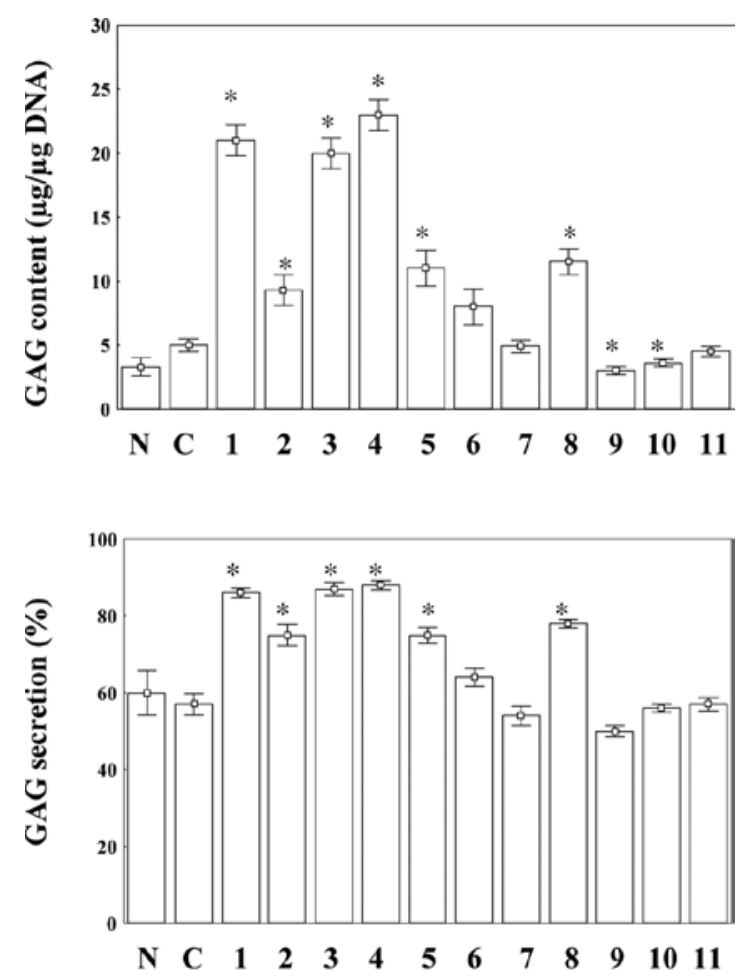

Figure 2. (A) Effect of compounds [1-11] on GAG content when applied at a concentration of $30 \mu \mathrm{M}$. (B) Secretion of compounds [1-11] in OI type I fibroblasts. Mean values \pm SD from three independent experiments performed in duplicate are presented. ${ }^{*} \mathrm{P}<0.05$ in OI-treated compared to -untreated cells (C). N, normal untreated cells.

molecular defect (20), a different GAG level was detected in comparison to their age-matched controls. The most marked discrepancies were detected in the fibroblasts of a more severely affected female patient (no. 2a) compared to her sibling (no. 2b), who had a milder phenotype. These findings suggest that alterations in GAG content, in addition to collagen type I defects, may be among the factors modulating OI phenotype. In the fibroblasts of patients with a mild form of OI type I and a detected 'null allele' in the COL1A1 gene (21), an approximate 1.5-fold increase in GAG concentration in medium was observed.

Previously, we studied the effect of various flavonoids on collagen biosynthesis in OI fibroblasts (10). Among these, the apigenin glycosides 7-O-glucuronide, 7- $\mathrm{O}$-methylglucuronide and pectolinarin specifically affected collagen biosynthesis without influencing the overall protein biosynthesis. Since these acted as stimulators of collagen type I biosynthesis, they have the potential to be used in the pharmacotherapy of patients with OI type I having a reduced amount of normal collagen. The names, number [no.] and structure of the compounds investigated in the present study are listed in Table I, with reference to Fig. 1.

Certain of the tested flavonoids used at the concentration of $30 \mu \mathrm{M}$ had quite the opposite effect on GAG content compared to their effect on collagen biosynthesis. Treatment of OI cells with the aglycones apigenin [1] and quercetin [4], which inhibited both collagen and non-collagen protein biosynthesis (10), caused the greatest increase in GAG concentration (Fig. 2A). Similarly, a different effect on GAG content was observed in contrast to the essential stimulatory
Table II. Content and distribution of sulphated GAGs in OI skin fibroblasts.

\begin{tabular}{|c|c|c|c|}
\hline OI type & Molecular defect & $\begin{array}{c}\mathrm{OI} / \mathrm{C}^{\mathrm{a}} \\
\text { (medium) }\end{array}$ & $\begin{array}{l}\mathrm{OI} / \mathrm{C}^{\mathrm{a}} \\
\text { (cell) }\end{array}$ \\
\hline$I(n=7)$ & Null allele (COL1A1) & $1.5 \pm 0.6$ & $1.0 \pm 0.3$ \\
\hline II & Gly388 $\rightarrow \operatorname{Arg}(C O L 1 A 1)$ & 8.1 & 5.0 \\
\hline \multirow[t]{3}{*}{ III } & Gly511 $\rightarrow \operatorname{Ser}(C O L 1 A 1)$ & 3.4 & 2.9 \\
\hline & $2 \mathrm{a}^{\mathrm{b}}$-deletion & 6.9 & 1.3 \\
\hline & $2 b^{b}$-deletion & 3.5 & 1.2 \\
\hline
\end{tabular}

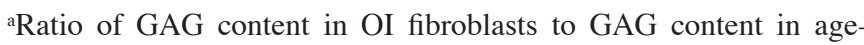
matched controls. ${ }^{b}$ Siblings whose fibroblasts secreted collagen type I with a lower molecular mass, suggesting deletion as a molecular defect.

activity of the apigenin glycosides [5] and [6] and pectolinarin [9] in collagen biosynthesis (10). The increase in sulphated GAG content in the presence of apigenin 7-O-glucuronide [5] was approximately 2 times lower than that observed in the presence of apigenin [1]. No effect was exerted on GAG levels by apigenin 7-O-methylglucuronide [6]. However, pectolinarin [9] caused a decrease in GAG content of $\sim 40 \%$. Of the other tested flavonoids, isokaempferide 7-O-glucoside [10] showed a similar effect to pectolinarin [9], decreasing GAG content by $\sim 30 \%$ (Fig. 2A). Similarly to apigenin 7-O-methylglucuronide [6], the apigenine [7] and quercetine [11] glucosides did not affect GAG content. The effects of the tested flavonoids on GAG concentration were not restricted to the OI cell lines, as we have obtained similar results following the treatment of normal cells.

The effect of the tested compounds on GAG secretion (assayed as the distribution of GAGs between the culture medium and the cell layer) was also examined. In the OI fibroblasts, the distribution of GAGs between the culture medium and the cell layer differed from that in control cultures, except in the cells of patients with OI type I, which secreted $~ 56 \%$ of the sulphated GAGs into the medium (Table II, Fig. 2B). Flavonoids, which at a concentration of $30 \mu \mathrm{M}$ caused a $\geq 2$-fold increase in GAG content [1-5] and [8], appeared to contribute to the significant increase in the secretion of GAGs from the cells (Fig. 2B). Among the compounds, apigenin 7-O-methylglucuronide [6] and pectolinarin [9] did not exert any effect on GAG secretion (Fig. 2B).

\section{Discussion}

Flavonoids are a large group of naturally occurring polyphenolic compounds with multiple biological functions. The fact that flavonoids interact with reactive oxygen species and influence the activity of a large variety of enzymes, ion channels and transcription factors determines a broad spectrum of their activity (11-13). Flavonoids and flavonoid-rich extracts have been implicated as beneficial agents in cancer, cardiovascular diseases and neurodegenerative disorders $(12,13)$, as well as in diseases associated with a disrupted collagen metabolism $(22,23)$. 
Previously, we studied the effect of flavonoids isolated from Cirsium rivulare (Jacq.) All. flowers and the Erigeron acris L. herb (14-16) on collagen biosynthesis in the skin fibroblasts of patients with OI to identify bioactive compounds with the potential for use in the pharmacological therapy of disease (10). Because of structural mutations in patients with OI types II, III and IV, which affect connective tissue through a dominant-negative mechanism, the goal of gene therapy is the selective suppression of mutant allele expression $(24,25)$. By contrast, in OI type I, bone formation is defective due to a deficiency of type I collagen caused by one null allele of the COL1A1 gene $(1,2,4,5)$, and agents that augment collagen production may have a beneficial effect. The benefits and short term safety of cyclic bisphosphonates have been reported in the literature; however, their long-term effects are still being investigated (25). Of the tested compounds, apigenin 7-O-glucuronide [5], apigenin 7- $O$-methylglucuronide [6] and pectolinarin [9], applied at a concentration of $30 \mu \mathrm{M}$, significantly induced collagen type I biosynthesis in the fibroblasts of OI type I patients, without affecting the levels of collagen type III or the overall protein synthesis (10).

With the exception of collagen, GAGs have been shown to participate in the formation of a functional supramolecular complex in the extracellular matrix $(9,26)$; whereas collagen fibers provide tensile strength, GAGs and PGs form a polysaccharide gel that resists compressive forces on the matrix. Specifically, PGs and their spatial arms, GAGs, are proposed to play an important role in the formation of collagen fibres and in the regulation of bone mineralization $(26,27)$. Therefore, it may be postulated that any abnormalities in GAG content and/or composition are implicated in certain clinical aspects of OI. In our research, increases in the concentration of extracellular sulphated GAGs were detected with greater alterations in the fibroblasts of patients with lethal and severe OI phenotypes (types II and III). The increase in GAG content may result from elevated GAG biosynthesis, as reported in OI type II skin fibroblasts (7), or may be due to increases in their sulphation (6). The increase in the level of GAGs was much smaller in the fibroblasts of patients with OI type I in comparison to OI patients with a more severe phenotype. However, an approximate 1.5 -fold increase in GAG content in medium and a decrease in collagen type I of approximately $50 \%$ (21) resulted in an approximate 3 -fold increase in the GAG to collagen type I ratio. Therefore, in the potential pharmacotherapy of OI type I with flavonoids, their effect on GAG level may be of clinical importance.

We found that some of the tested flavonoids influenced GAG content in quite the opposite way than they influenced collagen biosynthesis. For example, the greatest increase in GAG content was observed in OI fibroblasts treated with aglycones, which inhibited collagen biosynthesis (10). The most important factor influencing GAG level was the presence of at least one hydroxyl group at phenyl moiety, as in compounds [1] and [4] (Table I). The presence of methoxyl groups at C-3' and C-5' [2] markedly inhibited the increase in GAGs caused by compound [1], but their presence at C-3 with compound [3] had no effect. Similarly, in contrast to the essential stimulatory activity of the apigenin glycosides [5] and [6] as well as pectolinarin [9] in type I collagen biosynthesis, the flavonoids exerted different effects on GAG content. In cells treated with apigenin 7-O-glucuronide [5], an approximately 2 -fold reduction in the increase in GAG content was observed in comparison to apigenin [1]. No significant alterations were detected after treatment of cells with 7-O-methylglucuronide [6]. Furthermore, the presence of the $O$-rutinosyl group at C-7 and of two metoxy groups at C-6 and C-4' in pectolinarin [9] caused a decrease in GAG content of approximately $40 \%$ at a concentration of $30 \mu \mathrm{M}$.

In a previous study (10), we showed that apigenin 7-O-methylglucuronide [6] and pectolinarin [9] at a concentration of $30 \mu \mathrm{M}$ were stronger stimulators of collagen biosynthesis than apigenin 7-O-glucuronide [5]. Here, taking into account that, in most studied OI type I cell lines, no or little increase in total GAG content was observed, compounds [6] and [9] displayed greater beneficial action than compound [5]. We have also suggested that the stimulatory actions of [5], [6] and [9] on collagen biosynthesis probably involve different mechanisms, with [5] markedly inducing IGF-IR, while compounds [6] and [9] induce $\beta 1$-integrin expression (10). It has been suggested that IGF-IR plays an important role in the anabolic modulation of collagen synthesis by altering gene expression and prolidase activity (28). Increases in GAG content in OI cells in the presence of compound [5] could be the result of their increased synthesis. It was reported that IGF-I applied to skin fibroblasts increased the synthesis of PG and markedly stimulated the secretion of small PGs from cells (29). In fact, the treatment of OI fibroblasts with compound [5] caused an increase in GAG secretion in contrast to [6] and [9], which were expected to affect collagen synthesis through signals induced by the $\beta 1$-integrin receptor excitated by interactions with type I collagen (10). Thus, apigenin 7-O-methylglucuronide [6] has the potential to be used in OI type I patients with normal GAG level. However, in those with an increased GAG concentration, pectolinarin [9] may be more beneficial, acting by normalizing the GAG to type I collagen ratio, which plays a key role in fibrylogenesis.

\section{References}

1. Byers PH and Steiner RD: Osteogenesis imperfecta. Annu Rev Med 43: 269-282, 1992.

2. Cole WG: The molecular pathology of osteogenesis imperfecta. Clin Orthop 343: 235-248, 1997.

3. Sillence DO, Senn A and Danks DM: Genetic heterogeneity in osteogenesis imperfecta. J Med Genet 16: 101-116, 1979.

4. Prockop DJ: Mutations in collagen genes as a cause of connective-tissue diseases. N Engl J Med 326: 540-546, 1992.

5. Basel D and Steiner RD: Osteogenesis imperfecta: recent findings shed new light on this once well-understood condition. Genet Med 11: 375-385, 2009.

6. Engfeldt B and Hjerpe A: Glycosaminoglycans of cartilage and bone tissue in two cases of osteogenesis imperfecta congenita. Acta Pathol Microbiol Scand 84A: 488-494, 1976.

7. Kapoor R, Bourier S and Prehm P: Glycosaminoglycan synthesis in skin fibroblasts from patients with osteogenesis imperfecta. FEBS Lett 152: 183-186, 1983.

8. Grzesik WJ, Frazier CR, Shapiro JR, Sponseller PD, Robey PG and Fedarko NS: Age-related changes in human bone proteoglycan structure. Impact of osteogenesis imperfecta. J Biol Chem 277: 43638-43647, 2002.

9. Scott JE: Proteoglycan-fibrillar collagen interactions. Biochem J 252: 313-323, 1988.

10. Galicka A and Nazaruk J: Stimulation of collagen biosynthesis by flavonoid glycosides in skin fibroblasts of osteogenesis imperfecta type I and the potential mechanism of their action. Int $\mathrm{J}$ Mol Med 20: 889-895, 2007. 
11. Harborne JB and Baxter $\mathrm{H}$ (eds): The Handbook of Natural Flavonoids. Wiley \& Sons, Chichester, 1999.

12. Havsteen BH: The biochemistry and medical significance of the flavonoids. Pharmacol Ther 96: 67-202, 2002.

13. Vassallo N (ed): Polyphenols and Health. New and Recent Advances. Nova Science Publishers, Inc., New York, 2008.

14. Nazaruk J and Jakoniuk P: Flavonoid composition and antimicrobial activity of Cirsium rivulare (Jacq.) All. flowers. J Ethnopharmacol 102: 208-212, 2005.

15. Nalewajko-Sieliwoniuk E, Nazaruk J, Antypiuk E and Kojło A: Determination of phenolic compounds and their antioxidant activity in Erigeron acris L. extracts and pharmaceutical formulation by flow injection analysis with inhibited chemiluminescent detection. J Pharm Biomed Anal 48: 579-586, 2008.

16. Nazaruk J: Flavonoid compounds from Cirsium palustre (L.) Scop. flower heads. Biochem Syst Ecol 37: 525-527, 2009.

17. Barbosa I, Garcia S, Barbier-Chassefiere V, Caruelle JP, Martelly I and Papy-Garcia D: Improved and simple micro assay for sulfated glycosaminoglycans quantification in biological extracts and its use in skin and muscle tissue studies. Glycobiology 13: 647-653, 2003.

18. Labarca C and Paigen K: A simple, rapid and sensitive DNA assay procedure. Anal Biochem 102: 344-352, 1980

19. Galicka A, Wołczyński S, Leśniewicz R, Chyczewski L and Gindzieński A: A novel Gly to Arg substitution at position 388 of the $\alpha 1$ chain of type I collagen in lethal form of osteogenesis imperfecta. Acta Biochim Pol 49: 443-450, 2002.

20. Galicka A, Popko J, Wołczyński S and Gindzieński A Comparative studies of collagen in fibroblasts of patients with different intrafamilial expression of osteogenesis imperfecta. Postepy Osteoartrol 14: 87-90, 2003.

21. Galicka A, Bielawski T, Gindzieński A and Średzińska K Molecular diagnosis of osteogenesis imperfecta type I. Pol Merkur Lekarski 148: 345-348, 2008.
22. Phan TT, See P, Tran E, Nguyen TT, Chan SY, Lee ST and Huynh H: Suppression of insulin-like growth factor signaling pathway and collagen expression in keloid-derived fibroblasts by quercetin: its therapeutic potential use in the treatment and/or prevention of keloids. Br J Dermatol 148: 544-552, 2003.

23. Kapoor M, Howard R, Hall I and Appleton I: Effects of epicatechin gallate on wound healing and scar formation in a full thickness incisional wound healing model in rats. Am J Pathol 165: 299-307, 2004.

24. Niybizi C, Wang S, Mi Z and Robbins PD: Gene therapy approaches for osteogenesis imperfecta. Gene Ther 11: 408-416, 2004.

25. Cheung MS and Glorieux FH: Osteogenesis imperfecta: update on presentation and management. Rev Endocr Metab Disord 9: 153-160, 2008.

26. Hardingham TE and Fosang AJ: Proteoglycans: many forms and many functions. FASEB J 6: 861-870, 1992.

27. Rees SG, Shellis P and Embery G: Inhibition of hydroxyapatite crystal growth by bone proteoglycans and proteoglycan components. Biochem Biophys Res Commun 292: 727-733, 2002.

28. Miltyk W, Karna E, Wołczynski S and Pałka J: Insulin-like growth factor-I-dependent regulation of prolidase activity in cultured human skin fibroblasts. Mol Cell Biochem 189: 177-184, 1998.

29. Imai Y, Odajima R, Inoue Y and Shishiba Y: Effect of growth factors on hyaluronan and proteoglycan synthesis by retroocular tissue fibroblasts of Graves' ophthalmopathy in culture. Acta Endocrinol: 126, 541-552, 1992. 